\title{
Workplace Clinic
}

National Cancer Institute

\section{Source}

National Cancer Institute. Workplace Clinic. NCI Thesaurus. Code C114861.

An onsite healthcare facility that provides routine preventive services for its employees. 